\title{
PROGRAMA DE PÓS-GRADUAÇÃO EM ENFERMAGEM DA ESCOLA DE ENFERMAGEM ANNA NERY UNIVERSIDADE FEDERAL DO RIO DE JANEIRO: INOVAÇÕES CURRICULARES NO CURSO DE MESTRADO*
}

\author{
Maria Antonieta Rubio Tyrrell** \\ Suely de Souza Batista** \\ Ieda de Alencar Barreira** \\ Vilma de Carvalho**
}

\begin{abstract}
RESUMO: A escolha da temática está ligada aos vários aspectos críticos evidenciados fundamentalmente na organização da estrutura curricular do Mestrado em Enfermagem da EEAN/UFRJ, e do curso como um todo. A questão central contemplada, neste trabalho, refere-se às inovações curriculares no Mestrado, como resposta às exigências impostas, dentre outras, pela clientela, que no momento, é predominantemente o enfermeiro da assistência. A presenta resultados de processos de avaliação do curso, com participação de docentes, discentes e convidados (enfermeiros docentes e assistenciais).
\end{abstract}

ABSTRACT: The choice of the theme is connected to the many critical aspects shown essentially in the organization of the curricular structure of the Master Degree in Nursery at EEAN/UFRJ, and of the course as a whole. The central point approached in this article concerns the changes in the curriculum at the Master Degree level, as a response to the demands of the assisting nurses. It presents the results from a process of curriculum evaluation, in which teachers, students and invited professionals took part.

\section{INTRODUÇÃO}

A década de 70 representou para enfermagem uma etapa de grandes desafios, fundamentalmente, no que diz respeito à criação, fortalecimento e expansão dos Programas de Pós-Graduação em Enfermagem. Com 50 anos de sua criação, em 1972, a EEAN/UFRJ, propõe à enfermagem brasileira, o primeiro curso "stricto-sensu" na área, e em nível nacional. A propósito, a EEAN foi criada em 1922 junto ao Departamento de Saúde Pública e incorporada à Universidade do Brasil pela Lei no ${ }^{\circ} 452 / 1937$. No momento, é unidade integrante do Centro de Ciência da Saúde da Universidade Federal do Brasil - CCS/UFRJ. Neste ano de 1992, o Curso faz 20 anos, tendo formado 227 Mestres, para todas as regiões da Federação.

Vale considerar que, na fase anterior à implantação e implementação dos cursos de mestrados no Brasil, a enfermagem ressentia-se da falta de um corpo organizado de conhecimentos, ou pelo menos. do apoio de um quadro referencial devidamente classificado, ordenado, e que pudesse servir de apoio às pesquisas e à elaboração de teses. Ressentia-se também da pressão de fatores antecipadores de uma crise de transição, certamente denotativa de seu crescimento, de sua evolução e de sua expansão, sob o impacto mesmo das mudanças políticas e sociais.

No início dos anos 80 , ocorreram grandes modificações na vida política e social do país, caracterizadas por uma abertura que favoreceu, principalmente, à discussão e à crítica de todos os aspectos da vida brasileira. Na área da enfermagem, a década de 80 é marcada por uma significativa produção de trabalhos que analisam a aquisição científica e que indicam aos cursos de pós-graduação, as mudanças necessárias na enfermagem como profissão de saúde, e inovações imperativas no ensino da pós-graduação no Brasil.

A partir dessa década, a enfermagem passa a

* Tema livre a ser apresentado no 44 Congresso Brasileiro de Enfermagem - Brasília - DF. 05 a 09 de outubro de 1992.

** Docentes da Escola de Enfermagem Anna Nery - Universidade Federal do Rio de Janeiro 
situar-se frente à questão de identificar-se melhor como resposta às necessidades sociais. No bojo mesmo de sua crise de identidade, os estudos realizados ressaltam dificuldades tangíveis à sua natureza, escopo e contribuição social, exercício vivencial do assistir, do ensinar e do pesquisar. A imprecisão no reconhecimento de objetivos práticos e sociais reflete-se em certas incosistências e em certa inconstância na prática profissional dos indivíduos e dos grupos, e conseqüentemente, na prática da formação de recursos humanos em nível de pós-graduação. Nesse sentido, os estudos e o trabalho realizado nos cursos de pós-graduação no país, não chegaram a produzir o impacto capaz de favorecer a desejada excelência ou sequer a adequação a uma época de profundas transformações sociais.

Esta situação é descrita em detalhes nos discursos, temários e recomendações dos eventos da cate goria, que tratam de analisar e discutir a pós-graduação na enfermagem.

Numa atenção especial à formação de MESTRE EM ENFERMAGEM, aspecto bastante crítico na questão da pós-graduação em enfermagem, tenha-se em consideração as recomendações contidas nos "Relatório Final da Reunião de Coordenadores de Cursos de Pós Graduação em Enfermagem CAPES-1988" Nesse sentido, destaca-se desse relatório, o referente a "reavaliar a estrutura curricular dos cursos de pósgraduação, para atender à formação de docentes, de pesquisadores (e assistenciais) para assumir os desafios das transformações do setor de saúde e enfermagem".

\section{O CURSO DE MESTRADO DA EEAN/UFRJ}

\section{Implantação e credenciamento}

O curso de Mestrado em Enfermagem da EEAN/UFRJ, foi implantado em Agosto de 1972, no governo GEISEL, constituindo-se o primeiro curso "stricto-sensu" de enfermagem no Brasil.

O credenciamento* deu-se em 1973, pelo parecer CFE $\mathrm{N}^{\circ} 1.723 / 73$, e teve três $(03)$ recredenciamentos, a saber: 1979: $1^{\circ}$ recredenciamento, parecer CFE $n^{\circ}$ 2.308/79; 1986: $2^{\circ}$ recredenciamento, parecer CFE ${ }^{\circ}$
398/82; 1990: $3^{\circ}$ recredenciamento, parecer CFE ${ }^{\circ}$ 583/90 (período de 1982 a 1987).

O processo de avaliação do Curso deu-se pela CAPES (avaliações externas) e pelo Corpo Docente e Discente da EEAN (avaliações internas).

\section{Avaliação da CAPES}

Realizada através de visitas, por consultores designados pela CAPES, tendo obtido no período entre 1973 e 1984, conceito "A", e no período de 1985/1986, conceito "B" (a justificativa do conceito foi atribuída ao número de trancamento de matrículas, volume de disciplinas integrantes da estrutura curricular e "perfil evolutivo do curso"; especificando, esse conceito corresponde: corpo docente, B; atividades de ensino, A; o item atividades de pesquisas não foi avaliado por falta de informações). A última avaliação foi em 1990, conceito "B+".

\section{Avaliação da EEAN}

Realizada através de seminários externos e internos.

Em 1982, foi realizado um seminário nacional, com a finalidade de avaliar os 10 anos do Curso; em 1987, foi realizado um seminário de avaliação interno, com vistas ao recredenciamento; em 1989, o Seminário de Avaliação foi realizado por docentes e discentes com vistas à reavaliação da estrutura curricular.

Em 1990 e 1991, realizaram-se dois seminários de avaliação, com participação docente, discente e convidados, ${ }^{* *}$ visando reorientação e reordenação do currículo do curso, alvo do nosso tema.

\section{Administração do curso}

A partir de 1989, a administração do curso é feita por três professores, doutores ou livre-docentes, sendo que um é o Coordenador Adjunto. Os três integram a Comissão Adjunta do Curso de Mestrado, aspecto garantido no Regulamento do Curso.

* Comissão designada pela portaria n ${ }^{\circ}$ 118, Gb., do diretor do Departamento de Assuntos Universitários do MEC - Dr. Newton Sucupira e constituída pelas ilustres professoras: Maria Rosa S. Pinheiro e Amália Corrêa de Carvalho.

** - UNI-RIO, UERJ, UFF, UNB (Um docente de enfermagem de cada universidade), ex-alunos do Curso de Mestrado (enfermeiros docentes e assistenciais) e alunos dos Cursos de Graduação. 


\section{Carga horária}

O curso, desde sua implantação, teve um total de 1665 horas, divididas em 37 créditos de 45 horas cada. A partir de 1990, passou a ter 1620 horas, devido à exclusão da disciplina EPB (Estudo de Problemas Brasileiros), perfazendo um total de 36 créditos, de 45 horas cada.

\section{Corpo docente}

Na fase de implantação, constavam da proposta inicial vinte docentes. Destes, sete eram enfermeiros: seis da EEAN e uma da USP. Em 1986, treze eram docentes enfermeiros e, em 1989, já eram dezessete.

Os professores que participaram do Curso em 1990 e 1991, totalizam vinte e quatro. Destes dezessete eram da EEAN, um UERJ, umUFSC, um RP/USP, duas UFGO, uma UEGO.

\section{Número de vagas}

Desde sua criação (1972) o curso sempre ofereceu dez vagas. A partir de 1991, foram oferecidas quinze vagas. Cabe enfatizar que em 1974 e 1989, deu-se uma vaga para convênio BRASIL/PERU, e em 1991 uma vaga para convênio BRASIL/COLÔMBIA.

\section{Plano de capacitação docente}

Os vinte e quatro docentes do curso, possuem o título de "Doutor" ou "Livre Docente". No momento, duas têm o título de Doutor (USP), dez são doutorandas da EEAN (cinco iniciando o curso e cinco em fase de elaboração de tese). Uma doutoranda da EEAN tem previsão de defesa de tese para Agosto de 1992, constituindo-se a $1^{\text {a }}$ doutora do curso da EEAN/UFRJ; duas doutorandas realizam, no momento o curso fora da EEAN: uma na USP e outra na Universidade de Campinas, SP.

Tomando com base os dados anteriormente referidos, pode-se afirmar que o curso de mestrado da EEAN/UFRJ manteve-se coma mesma carga horária desde a sua implantação (apenas excluída a disciplina EPB); aumentou em $50 \%$ o número de vagas oferecidas (1990-1992). O corpo docente inicial foi consti- tuído por 20 docentes, sendo destes 7 enfermeiros (35\%). A partir de 1972, nota-se um aumento, progressivo de docentes enfermeiros, quanto ao número na ordem de $85 \%$ em 1986. sobre este total um acréscimo de $31 \%$ em 1989. Já em 1990 verifica-se um aumento de $41 \%$.

\section{ESTRUTURA CURRICULAR}

As mudanças atuais da estrutura curricular do curso de mestrado da EEAN, são produtos de um pré-seminário de avaliação discente e dois seminários de avaliação com participação de docentes, discentes e convidados, realizados em 1990 e 1991, respectivamente.

O $4^{\circ}$ seminário( 19 a 20/9/90) teve como objetivos:

a) Fazer uma reflexão crítica sobre a situação atual do curso; b) indicar diretrizes fundamentais para a reorientação do curso*, face às recomendações da CAPES/1988, do $3^{\circ}$ seminário de avaliação EEAN/1989, do parecer $\mathrm{CFE}^{\circ} 5831990$ e da reunião CAPES, 1990; c) propor medidas concretas que viabilizam tal reorientação.

O $5^{\circ}$ Seminário (2 e 8/10/91), visando dar continuidade ao $4^{\circ}$ sem. de avaliação do curso, estabeleceu dois (02) objetivos: a) propor diretrizes para adequação das áreas de concentração à atual proposta de mudanças introduzidas no currículo do curso de mestrado e b) discutir as propostas dos programas de áreas de concentração, tendo em vista as diretrizes emanadas do $1^{\circ}$ seminário. Cabe esclarecer que o $1^{\circ} \mathrm{sem}$. de avaliação do curso efetuou-se em dois momentos; o primeiro em 2 de outubro e o segundo em 8 do mesmo mês.

Toma-se como referência aqui, para melhor objetivar as mudanças na estrutura curricular do curso, aquela que permaneceu até 1989 , a seguir:

a) Domínio conexo 12 créd.

b) Áreas de concentração

- disciplinas obrigatórias comuns às áreas: 08 créd.

- disciplinas obrigatórias para cada área 08 créd.

c) Disciplinas eletivas ............................. 08 créd.

d) Tese ......................................................... 00 créd.

* Considerando que o enfermeiro que procura o curso é, no momento, mormente o enfermeiro assistencial ou aquele que acumula o cargo docente e técnico. 
A seguir descrevemos esta estrutura para melhor objetivar as inovações:

a) Disciplina do domínio conexo:

- Didática Especial ................................ 2 créd.

- Psicologia da Aprendizagem ............. 2 créd.

- Seminário sobre Currículo

de Enfermagem ................................. 1 créd.

- Estudos dos Problemas Brasileiros .... 1 créd.

- Metodologia da Pesquisa II ............... 2 créd.

- Fundamentos para uma

Filosofia da Enfermagem ................... 2 créd.

- Seminário de Legislação e

Ética de Enfermagem 2 créd.

b) Áreas de Concentração

* Disciplinas Obrigatórias, comuns às áreas:

- Concepções Teóricas da

Enfermagem 1 créd.

- Metodologia de Assistência

de Enfermagem II 2 créd.

- Estratégia de Enfermagem

Assistencial 1 créd.

- Metodologia do Ensino de

Enfermagem 2 créd.

- Seminário para Tese de Mestrado ..... 1 créd.

* Área de Enfermagem Fundamental

- Estudo Crítico dos Programas de

Enfermagem Fundamental .... 2 créd.

- Análise Crítica do Ensino de Enfermagem Fundamental . 2 créd.

- Desenvolvimento do Ensino/Aprendizagem em Enfermagem Fundamental ... 4 créd.

- Pesquisa Tese de Mestrado 0 créd.

* Área de Metodologia da Enfermagem

- Metodologia da Assistência de Enfermagem II 3 créd.

- Processo Administrativo e sua Aplicação na Assistência de Enfermagem ........... 3 créd.

- Pesquisa Tese de Mestrado ................. 0 créd.

- Logística do Serviço de Enfermagem 2 créd.

\section{* Área Enfermagem Assistencial}

Núcleo de Enfermagem Psiquiátrica

- Problemática do Ensino de

Enfermagem Psiquiátrica

2 créd.

- Enfermagem Psiquiátrica I ................ 3 créd.

- Enfermagem Psiquiátrica II ............... 3 créd.

- Pesquisa e Tese de Mestrado .............. 0 créd.
Núcleo de Enfermagem Médico-Cirúrgica

- Pesquisa Tese de Mestrado 0 créd.

- Pragmática de Enfermagem

Médico-Cirúrgica. 3 créd.

- Analítica da Situação da Enfermagem

Médico-Cirúrgica. 2 Créd.

- Problemática do Ensino de Enfermagem

Médico-Cirúrgica. 3 Créd.

Núcleo de Enfermagem em Saúde da Comunidade

- Enfermagem na Saúde da

Comunidade 3 Créd.

- Analítica das Situações de Enfermagem

na Saúde da Comunidade 2 Créd.

- Pragmática de Enfermagem na Saúde da Comunidade 3 Créd.

- Pesquisa Tese de Mestrado 0 Créd.

c) Disciplinas Eletivas

- Farmacologia Aplicada à

Enfermagem 1 Créd.

- Teoria das Organizações ...................... 3 Créd.

- Metodologia Científica ...................... 1 Créd.

- Psicologia do Desenvolvimento ........ 1 Créd.

- Estratégias de Enfermagem na

Saúde Mental 1 Créd.

- Dinâmica do Relacionamento

Humano. 1 Créd.

- Bioquímica E 2 Créd.

Tópicos Especiais em

Antropologia 3 Créd.

Logística do Serviço de

Enfermagem.... 2 Créd.

Aplicação da Teoria das Organizações

à Enfermagem 1 Créd.

Métodos Qualitativos de Pesquisa.... 1 Créd.

Métodos e Técnicas de Pesquisa ....... 1 Créd.

Enfermagem no Planejamento do

Setor Saúde 1 Créd.

Enfermagem e Assistência Integral

à Saúde 1 Créd.

- Epidemiologia Social 1 Créd.

- Tópicos Especiais em Sociologia ...... 3 Créd.

- Fenomenologia e Hermenêutica ........ 3 Créd.

- Imunologia Básica 1 Créd.

- Bacteriologia Médica Aplicada à Enfermagem 1 Créd.

- Estatística para Ciências

Biológicas 2 Créd.

- Pedagogia Médica 2 Créd. 


\section{Estrutura curricular modificada}

A partir de 1990, e a estrutura curricular passa a ter as seguintes áreas:

a) Domínio Básico (conexo) 10 Créd.

b) Disciplinas Eletivas ........................ 8 Créd.

c) Áreas de Concentração ................... 8 Créd.

d) Tese

10 Créd.

Perfazendo um total de 36 créditos, equivalente a 1620 horas (valor do crédito $45 \mathrm{~h}$ ).

\section{a) Domínio Básico}

Compreende dez créditos, abrangendo obrigatoriamente as quatro áreas de atuação profissional (ensino, assistência, administração e pesquisa), com opções entre as seguintes disciplinas:

* Obrigatórias:

- Metodologia da Pesquisa II 3 Créd.

- Seminário de Tese de Mestrado 2 Créd.

* Optativas

- Práticas de Estágio Curricular

- Pragmática de Enfermagem

Assistencial 3 Créd.

- Tópicos de Educação Continuada

- Seminário sobre Problemática do

Ensino de Enfermagem

- Seminário sobre Regulamentação da Enfermagem e Ética Profissional

- Enfermagem e Sociedade

- Processo de Trabalho em

Enfermagem

- Enfermagem no Planejamento do

Setor de Saúde

- Seminário de Temas Emergentes da

Prática Profissional

- Analítica das Situações de

Enfermagem

- Problemática do Ensino de Enfermagem

em Campos de Prática

3 Créd.

2 Créd.

3 Créd.

3 Créd.

2 Créd.

2 Créd.

2 Créd.

2 Créd.

2 Créd.

2 Créd.

\section{b) Disciplinas Eletivas*}

Cada mestranda(o) deverá cumprir oito (08) créditos dentre as seguintes disciplinas:

- Didática Especial

2 Créd.

- Fundamentos para uma Filosofia de

Enfermagem

3 Créd.

- Filosofia da Educação.

3 Créd.

- Dinâmica do Relacionamento

Humano

2 Créd.

- Tópicos Especiais em

Antropologia.

3 Créd.

- Tópicos Especiais em Sociologia .

3 Créd.

- Psicologia da Aprendizagem

2 Créd.

- Psicologia da Personalidade I

2 Créd.

- Psicologia do Desenvolvimento

2 Créd.

- Psicologia Social I

2 Créd.

- Modelos Alternativos de Enfermagem

Assistencial

2 Créd.

- Práticas Alternativas de Saúde ......... 2 Créd.

- Métodos Qualitativos de Pesquisa.... 3 Créd.

- Fenomenologia e Hermenêutica........ 3 Créd.

- Estratégias de Enfermagem na

Saúde Mental

2 Créd.

- Pedagogia Médica

2 Créd.

- Anatomia Básica e Funcional

- Farmacologia aplicada à

Enfermagem

2 Créd.

- Imunologia Básica

2 Créd.

- Bacteriologia Médica Aplicada à

Enfermagem.

- Estatística para Ciências

Biológicas

- Métodos e Técnicas em Pesquisa

2 Créd.

- Teoria das Organizações.

2 Créd.

- Bioquímica Aplicada à

Enfermagem.

- Tópicos Especiais em Enfermagem
- Questões de Metodologia e Teoria

Histórica.

- Concepções Teóricas da

Enfermagem.

2 Créd.

- Reflexões sobre a História da

Enfermagem

2 Créd.

- Seminário de Enfermagem

Assistencial
2 Créd.

\footnotetext{
* $\quad$ Podem ser oferecidas também por outras instituições da UFRJ (IFCS, ICB, FE, FP, FCH, NUTES, etc.) e fora da UFRJ (ENSP,
} UERJ - Ciências Políticas, UFF, UNI-RIO, etc.) 


\section{c) Áreas de Concentração}

\section{ENFERMAGEM E MUDANÇA SOCIAL}

Elenco de Disciplinas

- Questão Humana e Ecologia na

Enfermagem 2 Créd.

- Enfermagem, História e Demandas

Sociais

3 Créd.

- Da Enfermagem e de seus Clientes:

Ética Profissional e Deontologia ....... 3 Créd.

A ENFERMAGEM NO CONTEXTO DE SAÚDE

Elenco de Disciplinas

- Logística e Gerencia em

Enfermagem

3 Créd.

- Modelos Assistenciais em Saúde e

Enfermagem

3 Créd.

- Políticas em Saúde e Enfermagem .... 2 Créd.

d) Tese

Compreende o Seminário de Tese com 02 Cred. e 08 Cred. para o desenvolvimento da tese, até a dissertação ou defesa de tese de mestrado.

\section{JUSTIFICATIVAS}

\section{a) Sobre as disciplinas do Domínio Básico ou Conexo}

As duas (02) disciplinas obrigatórias totalizam $50 \%$ dos créditos desse domínio e atendem às diretrizes do $4^{\circ}$ Seminário de Avaliação do Curso de Mestrado da EEAN/UFRJ, quais sejam:

- Adotar como elemento fundamental de integração horizontal (eixo condutor) do Curso de Mestrado o processo de elaboração da tese.

- Reordenar as atividades do Curso de Mestrado, de modo a adequar seu ritmo, seqüência e estratégias de ensino-aprendizagem, às características do ensino teórico-prático dos Programas Curriculares Interdepartemantais (PCIs) do Curso de Graduação da EEAN.

- Com base nas discussões, essas diretrizes representam verdadeiros pilares para a construção do saber da enfermagem e para o aprofundamento de conhecimentos teórico-práticos nas áreas de atuação profissional da(o) enfermeira(o).

- As demais disciplinas optativas compreendem, também, $50 \%$ do total de créditos do domínio básico (ou conexo). Dentre essas disciplinas, cada mestranda(o) poderá selecionar as que melhor atendam aos seus interesses profissionais ou de investigação.

Vale ressaltar que, já nesta fase da estrutura curricular, o papel do orientador acadêmico (ou orientador de tese) é fundamental na ajuda à construção dos planos de estudo.

Outro aspecto importante quanto a este domínio é que, na oportunidade da seleção de disciplinas de créditos optativos, caso a(o) mestranda(o) considere outras disciplinas desse domínio adequada, a seu plano de estudo, excedendo os $50 \%$ exigidos, as disciplinas selecionadas a mais, serão consideradas ELETIVAS.

\section{b) Disciplinas Eletivas}

Especificamente sobre as disciplinas eletivas, cabe esclarecer que são oferecidas à seleção pelas(os) mestrandas(os), para a construção dos planos de estudo, como suporte ou apoio essencial ao aprofundamento do conhecimento em geral e ao domínio da prática profissional, em que pesem as áreas de atuação da enfermagem - ensino, assistência, administração e pesquisa. Nesse particular, a idéia principal é a de que as disciplinas eletivas possam apoiar, efetivamente, as proposições da(o) mestranda(o) nos trabalhos individuais e coletivos, e na elaboração mesma das teses. Para tanto, o elenco das disciplinas eletivas, tal como indicado, não deve limitar a possibilidade de opção das(os) mestrandas(os) quanto aos planos de estudo e, por conseguinte, a seleção das eletivas pode incidir também sobre disciplinas que são oferecidas por outras unidades de ensino, dentro e fora da UFRJ, desde que o orientador acadêmico (ou orientador de tese) julgue da conveniência das mesmas, em que pese o plano de estudo ou projeto de pesquisa.

\section{c) Sobre as Áreas de Concentração}

De conformidade com a Proposta de Introdução de Mudanças na Estrutura Curricular do curso de Mestrado em Enfermagem da EEAN/UFRJ - 1990, resultante do $4^{\circ}$ Seminário de Avaliação do Curso de Mestrado, foi estabelecido que as áreas de concentração abrangeriam, em cada programa específico, oito (08) créditos, permanecendo - quanto aos objetivos, conteúdos e experiências teórico-práticos - tal como constavam da renovação de recredenciamento (Parecer 583/90 - CFE) até a oportunidade de uma nova e específica avaliação.

Tal avaliação ocorreu, de fato, com o 5o Seminário de Avaliação do Programa de Pós-Graduação em Enfermagem, nível de Mestrado, realizado nos dias 2 e 8 de outubro de 1991. 
Convém mencionar que a Área de Concentração ficou entendida como a etapa curricular dos Programas de Pós-Graduação a nível de Mestrado em Enfermagem, podendo servir tanto aos estudos com vistas a maior abrangência de visão sobre os termos e temas que interessam à enfermagem moderna, quanto ao aprofundamento do domínio sobre o saber e a prática da(o) enfermeira(o) no contexto social e, mais particularmente, nas áreas de atuação profissional.

Todavia, em virtude dos estudos sobre a Pós-Graduação, ficou convencionado que cada Área de Concentração deveria ser reconhecida, plenamente, como a culminação de um Programa de Mestrado em Enfermagem. O que se quer dizer com isto é que, cada Área de Concentração representa, em termos acadêmicos e curriculares, um programa por inteiro, com todas as implicações administrativas e de ensino, não obstante a estrutura curricular (domínio básico ou conexo, disciplinas eletivas e tese) possa ser a mesma para todos os programas de Pós-Graduação a nível de Mestrado da EEAN/UFRJ.

Assim sendo, os programas das Áreas de Concentração requerem que suas propostas e desenvolvimento dependam dos esforços de professores, reunidos em equipes ou grupos organizados por temas, ou núcleos de conhecimento, e de interesse pragmático.

Vale destacar que, em razão das vagas oferecidas e esforços docentes requeridos, em cada programa, coloca-se como recomendável que, em cada período letivo, sejam oferecidos três Programas de Pós-Graduação a nível de Mestrado, ou no mínimo dois, prevendo-se o rodízio de docentes das Áreas de Concentração propostas. Nesse sentido, e importante enfatizar a necessidade de um plano de projeção para tais Programas, com antencedência de dois anos, sujeito a arranjos e negociações circustanciais à luz das possibilidades dos recursos humanos existentes nos vários Departamentos, em que pesem as limitações institucionais e demandas do Curso.

A nova proposta para os programas das Áreas de Concentração baseou-se principalmente nas temáticas dos ante-projetos de tese apresentados pelas mestrandas, na disciplina SEMINÁRIO DE TESE DE MESTRADO.

Deste modo, para o período letivo $1991 / 2^{\circ}$, os programas das Áreas de Concentração são apenas dois, posto que além de servirem aos objetivos e estudos aos projetos de tese, foram detidamente consideradas as possibilidades e limitações institucionais quanto à distribuição de docentes e orientadores de tese para atender à demanda.

\section{d) Sobre a Tese}

Quanto ao processo de elaboração de Tese, torna-se imprescindível considerar que dentre dez créditos atribuídos, dois correspondem à disciplina SEMINÁRIO DE TESE DE MESTRADO, a qual oferece às(aos) mestrandas(os) a oportunidade de apresentar e discutir seus projetos de tese com professores, orientadores e outros docentes interessados, favorecendo com isso a apreciação crítica das metodologias, dos temas e dos quadros referenciais propostos. Essa disciplina tem como pré-requisito a disciplina METODOLOGIA DA PESQUISA II. Os oito créditos restantes são destinados ao desenvolvimento, defesa de tese ou dissertação.

\section{CONSIDERAÇÕES FINAIS}

A título de conclusão, cabe referir que também foi discutido no $5^{\circ}$ Seminário de Avaliação do Programa de Pós-Graduação em Enfermagem, nível de Mestrado, da EEAN/UFRJ, outras inovações:

- a possibilidade de a(o) enfermeira(o), matriculada(o) num programa de Pós-Graduação a nível de Mestrado, poder optar ou por concluir este programa, o que significa cumprir todas as exigências próprias do curso, ou poder optar por continuar seus estudos num programa de Doutorado. $\mathrm{O}$ que significa que $\mathrm{a}(\mathrm{o})$ aluna(o) precisará ter cumprido os 26 créditos do programa em nível de Mestrado e ter conseguido preencher os requisitos do programa de seleção a nível de Doutorado; ou seja, ser selecionada(o) para ocupar uma das vagas oferecidas por este Programa;

- outros programas de Áreas de Concentração poderão ser propostos a partir de $1992 / 1^{\circ}$, desde que atendam à temática dos ante-projetos de dissertação de mestrado apresentado pelos candidatos e/ou alunos do curso,aos núcleos de conhecimento e de interesse pragmático de equipes docentes da Instituição e à aprovação pelos Colegiados competentes;

- a possibilidade de incluir como discente, o aluno em "condição especial", isto é, aquele que, sem prestar os exames do processo de seleção, inscreve-se em disciplinas, podendo aproveitá-las após a aprovação na seleção;

- a coordenação das disciplinas e das áreas de concentração são realizadas em caráter de colegiado. 
não mais por um único docente, oportunizando desta forma a experiência a todos os docentes envolvidos e assegurando-lhes também a partici- pação na programação, execução e avaliação acadêmica.

\section{BIBLIOGRAFIA}

1. BARREIRA, Ieda de Alencar e col. Acerca da PósGraduação na EEAN/UFRJ. Documento Base do IV Seminário de Avaliação do Mestrado. RJ. 1990. (mimeo).

2. CARVALHO, Vilma e col. Relatório dos Cursos de Pós Graduação em Enfermagem da EEAN. Apresentado na Reunião de Coordenadores dos Cursos de Pós-Graduação promovido pela CAPES, Brasília-DF. 1990 e 1991.

3. ELSAS, Berenice Xavier e col. A estrutura curricular do curso de Mestrado até 1989. Documento Base do V Seminário de Avaliação do Mestrado. RJ. 1991. (mimeo).
4. ESCOLA DE ENFERMAGEM ANNA NERY - EEAN. Enfermagem: 10 anos do Curso de Mestrado. Editora da UFRJ. Vol. I. $n^{\circ} 1.1988$.

5. TYRELL, Maria Antonieta Rubio e col. A estrutura curricular do Curso de Mestrado, Proposta de Inovações. Documento Base do V Seminário de Avaliação do Mestrado. RJ. 1991. (mimeo).

6. e BAPTISTA, Suely de Souza. Relatório do Curso de Mestrado da EEAN. RJ. 1991. (mimeo). 